\title{
Relative development in stock markets: empirical evidence from mainland China and Hong Kong
}

\author{
DAUVIN J. PETERSON, SCOTT PARDEE $\uparrow$ and \\ PHANINDRA V. WUNNAVA*† \\ Deutsche Bank AG, Hong Kong Branch, Global Investment Banking, Private Equities, \\ Cheung Kong Center 55/f, 2 Queen's Road Central, Hong Kong and † Department of \\ Economics, Middlebury College, Middlebury, VT 05753
}

Factors that might explain the relative growth of the stock markets of Hong Kong and Mainland China in recent years and the different responses of these markets to the 1997 Asian financial and economic crisis are empirically analysed. These factors are used to project the growth of total market capitalization of the two markets in the future. Clearly, Hong Kong, with its open economy and financial markets, was strongly affected by the Asian crisis, whereas Mainland China, with many restrictions on capital flows still in place, was less affected. The results indicate that the Mainland Chinese stock market is still developing, and forecast models suggest that Mainland China's market will overtake Hong Kong's market in size, but may become the more volatile of the two markets, especially as China relaxes its restrictions on international capital flows.

\section{BACKGROUND}

China, with approximately one quarter of the world's population, is poised to become a major economic force through increased integration with global capital markets as a result of its entrance into the World Trade Organization (WTO). A comparison of the Hong Kong stock market and the Chinese stock market over the past five years provides an indication that the Chinese stock market has the potential to surpass the value of the Hong Kong stock market. The lack of volatility of the Chinese stock market during the 1997 Asian economic collapse, combined with the pure size of the Chinese economy, make it possible that its stock market will become Asia's largest over the next five years, given a positive investment environment for foreign firms. A brief history of China's stock exchanges and their historical performance as com- pared to Hong Kong will provide a base from which to analyse the empirical results presented in this paper.

China's two stock exchanges in Shanghai and Shenzhen opened their doors to trading in late 1990. Since then, the market capitalization of each exchange has grown rapidly. In 1992, the combined total market capitalization of the Shanghai and Shenzhen exchanges was 104.8 billion Chinese yuan ${ }^{1}$ (approximately US\$12.7 billion). The 1998 combined market capitalization of the two exchanges grew to 1950.5 billion Chinese yuan (approximately US\$236 billion). As of August 2000, this number had reached US\$521.3 billion. $^{2}$

The stock exchanges in China are divided into foreign and domestic boards. The A-share market is for domestic investors and the B-share market is for foreign investors. As of 15 January 2001 there were 1031 companies listed on the A-share board and 113 listed on the B-share board. As

\footnotetext{
*Corresponding author. E-mail: Wunnava@middlebury.edu

${ }^{1}$ The exchange rate for the Chinese yuan used in this paper is 8.27 per US dollar. The fluctuation of this exchange rate between January 1995 and March 2001 has been between 8.277 and 8.438 yuan per US dollar.

2 Bloomberg.
} 
a point of reference, the number of Chinese companies that list both A and B shares is very small compared to the total number of listed firms in the A share market. As of 1998, only 80 of 807 listed companies had listings on both boards. Trading volume for the Mainland's stock exchanges has skyrocketed over the last ten years. In 1992, the volume of shares traded on the Shanghai and Shenzhen exchanges was 3.8 billion, and by 1998, the annual volume of shares traded had reached 215 billion shares. ${ }^{3}$

In November 2000, Chinese officials announced that by mid-2001 the Shanghai and Shenzhen boards would be merged, in a move towards a unified stock market in Mainland China. This reorganization includes creating a single listing board similar to the Nasdaq board in the United States and also a move towards equal share ownership rights for domestic and foreign investors. This extremely important development made the study of China's Ashare market prior to foreign influence an interesting study.

China's economy has been strong and resilient, as can be seen from the 1997 Asian economic crisis in which Hong Kong and other previously strong Asian countries suffered from speculative attacks and loss of investor confidence. This is indicated by the historical total market capitalization of the Shanghai and Shenzhen stock exchanges. ${ }^{4}$ As seen in Fig. 1, the Hong Kong total stock market capitalization declined from around US\$600 billion in mid-1997 to
US\$300 billion in late 1998. This is a result of the speculative attacks as investors pulled money from the market and the share prices of most companies fell below levels not seen prior to 1997. The combined market capitalization of the Shanghai and Shenzhen stock exchanges rose from approximately US $\$ 180$ billion to US $\$ 260$ billion during the same period. ${ }^{5}$

Evidence that Mainland China's stock markets are growing at a faster rate than the developed market of Hong Kong raises the question of where foreign firms should position their investments over the next few years. To determine this, it is necessary to analyse the historical returns of each market and then forecast different scenarios for future valuations based on regression results to determine a range of future volatility for the two markets.

\section{EMPIRICAL MODEL AND VARIABLES}

The total market capitalization of the stock exchanges in Hong Kong and China will be studied to investigate the effects of the Asian economic collapse. In addition, these models will be aimed at searching for signs of recent development in the Chinese A-share market. This variable is the best representation of the underlying asset values in an economy, and thereby proxies for the underlying investment environment. During the Asian crisis, the decline of

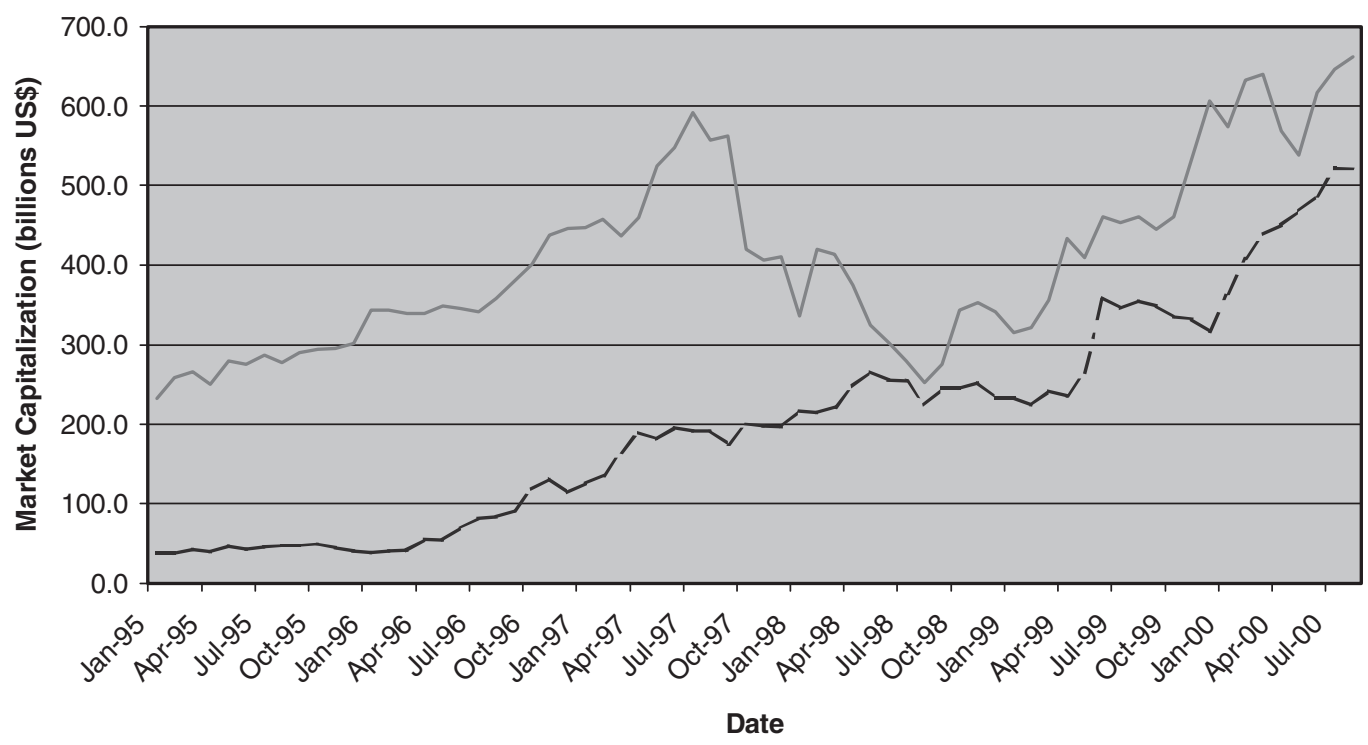

Source: Bloomberg

- - - Shanghai and Shenzhen Hong Kong

Fig. 1. Total market capitalization of Hong Kong/Shanghai and Shenzhen stock markets: January 1995-August 2000

\footnotetext{
${ }^{3}$ China Securities Regulatory Commission.

${ }^{4}$ Total market capitalization is the total dollar value of all shares listed on a particular exchange.

${ }^{5}$ Bloomberg.
} 
total market capitalization in Hong Kong reflected the rapidly declining investment environment; however, the value of the Chinese stock market continued to grow, which indicated that the investment environment was still thriving. The Hong Kong model uses monthly observations between January 1995 and February 2000. In the model of Chinese stock markets, the timeframe for the data is December 1996 through December 1999. Additionally, the data for the Shanghai and Shenzhen Ashare stock markets was combined to reflect the merger of these two markets in $2001 .^{6}$

The independent variables chosen to predict market capitalization are a combination of primary economic indicators in developed economies and other variables, which have been presented in previous studies of markets. Lending rate and changes in consumer prices are 'macro' economic indicators. The lending rate $(L R)^{7}$ is the rate at which individuals and businesses borrow money, and this cost is expected to have a negatively affect the value of a stock market. Consumer price changes $(C P)$ are a proxy for inflation, which indicate the relative state of the investment environment. Again, a negative impact on the market capitalization of the stock market is hypothesized.

Volume $(V)$ is used as measure of liquidity to test the hypothesis that higher liquidity leads to increasing stock market capitalization. In his analysis of the US Treasury market, Fleming (2000, p. 133) outlines three measures of liquidity in a market; bid-ask spread, depth of the market, and volume. Volume is an imperfect measure of liquidity, however it was the most suitable mainstream market indicator from which to test the hypothesis that higher liquidity is positively correlated with stock market capitalization.

The spread between the yield of government treasuries in Hong Kong (or China) and the United States government treasury $(T R)$ can be used as a measure of the risk premium required by foreign and domestic investors. Fernald et al. (1998) determined that this spread represented the risk premium required by foreign investors. ${ }^{8}$ The risk-premium variable has been included in the model for China's Ashare market for consistency; however its predicting power can be assumed to be minimal because a variable meant to reflect risk to investors in a foreign market is not likely to have significant predicting power for a market not influenced directly by foreign investors.

The exchange rate for the Thai baht $(T B)$ was added to the models in order to better capture structural shifts that occurred as a result of the 1997 Asian economic crisis. The devaluation of the baht was a signal to investors that economic fundamentals in the Asian economies had deteriorated; therefore local and foreign investors pulled money out of Asian stock markets.

The following model was developed to study the relationship between the independent variables and the total market capitalization of the Hong Kong and Mainland China stock market: ${ }^{9}$

$$
\begin{aligned}
M C A P_{t}= & \beta_{0}+\beta_{1} C P_{t}+\beta_{2} V_{t}+\beta_{3} T R_{t}+\beta_{4} L R_{t}+\beta_{5} T B_{t} \\
& +\lambda_{0} D_{t}+\lambda_{1}(C P \cdot D)_{t}+\lambda_{2}(V \cdot D)_{t} \\
& +\lambda_{3}(T R \cdot D)_{t}+\lambda_{4}(L R \cdot D)_{t}+\lambda_{5}(T B \cdot D)_{t}+\varepsilon_{t}
\end{aligned}
$$

The objective of the Hong Kong model was to prove that a structural shift had taken place during the 1997 Asian economic crisis, and the objective for the Chinese model was to test for development of the A-share market between 1996 and 1998.

All data for these models is from Bloomberg except for the trading volume of the Mainland China stock markets. This data is courtesy of Deutsche Bank, Hong Kong and Datastream.

A breakpoint model with intercept and interaction dummies was developed for Hong Kong to test for the existence of a structural shift in the economy as a result of the 1997 Asian economic crisis. Looking at the total market capitalization of the Hong Kong stock market in Fig. 1, a clear start and end of the 1997 crisis can be identified. The time period between July 1997 and November 1998 was chosen to represent the crisis period, and a Chow's breakpoint test proved the validity of the chosen dates. ${ }^{10}$ The model for Mainland China has a breakpoint at September 1998, which reflected a time at which the Asian economic crisis

\footnotetext{
${ }^{6}$ Leggett (2000). This article reported that the Shanghai and Shenzhen A-share stock exchanges would be merged, and compared the combined total market capitalization of these two exchanges against the total market capitalization of the Hong Kong stock exchange to demonstrate the growing presence of China's stock markets in Asia. It follows that this study looks to historically combine the data in order to look at the growth of these markets in recent years.

${ }^{7}$ The International Monetary Fund defines the lending rate for Hong Kong and China as the rate on working capital loans set by HSBC (the Hong Kong and Shanghai Banking Corporation) and the Bank of China respectively. China's reported lending rate is for loans of one year or less maturity, but maturity is not specified for Hong Kong. The previous data descriptions are from Bloomberg.

${ }^{8}$ The Hong Kong model uses yields from a 1-year Treasury bond, and the China model uses a JP Morgan index of government bonds. ${ }^{9}$ This equation may be considered a variant of the multifactor equilibrium models specified in the Arbitrage Pricing Theory (APT) to explain returns on investments in securities. Ross (1977) and others developed the APT, which has many betas, in light of the criticisms of the single-factor Capital Asset Pricing Model (CAPM), which has only one beta. The academic literature surrounding APT, pro and con, continues to grow, and APT models are widely used by analysts in financial and industrial firms.

${ }^{10}$ The value of the breakpoint $F$-test $(12,46)$ for the Hong Kong model was 12.44 , which allowed a rejection of the null that no structural shift of Hong Kong's economy had occurred as a result of the 1997 financial crisis.
} 
was coming to a close and the Chinese government had stepped up its pursuit of WTO membership. ${ }^{11}$

\section{RESULTS AND FORECASTS}

The regression results ${ }^{12}$ for both Hong Kong and China are displayed in Table 1.

\section{Hong Kong regression results}

The regression results of the Hong Kong model provide compelling evidence that the total market capitalization of a stock market acts as a proxy for the underlying investment environment in an economy. The estimated coefficients for changes in consumer prices $(C P)$, a measure of inflation, were in line with expectations for noncrisis periods by having a large negative impact on total stock market capitalization. During the crisis period, however, this value became significantly positive, indicating that inflation acted as a proxy for a positive trend in Hong Kong's economy during the crisis period.

An increase in the cost of lending $(L R)$ seems to be a strong factor when other regional economies are in crisis, but when there are no economic crises in sight, higher lending rates do not negatively impact investor confidence. The lending rate had a negative relationship with total market capitalization only during the crisis period. Volume (V), as a measure of liquidity, was statistically significant in this model, but not economically significant as shown by the small estimated coefficient. This study of the Hong Kong stock market did not find compelling evidence that higher liquidity in markets, as measured by volume, leads to large market capitalization.

Increasing spreads between the US and Hong Kong government bond yields $(T R)$ are negatively associated with the value of the Hong Kong stock market. When investors begin to require higher returns on a government bond, it sends a clear signal to the market that a declining investment environment exists. This was evident for both noncrisis and crisis periods in Hong Kong. Finally, the Thai baht $(T B)$ exchange rate variable yielded interesting results. A positive relationship between devaluation and the total market capitalization of the Hong Kong stock market during a crisis may have been the result of investors having taken money out of regional markets and have moved it into Hong Kong as a short-term haven from the crisis.

\section{Chinese regression results}

The results showed conclusive evidence that development of China's stock markets occurred during the specified three-year period. In particular, the estimated coefficients for lending rate $(L R)$ and change in consumer prices $(C P)$ reflect a significant increase in domestic investors' acknowledgement of and reaction to 'macro' economic indicators.

As shown by the results of the model for the developed Hong Kong stock market, the lending rate and changes in consumer prices are indicators that are strongly heeded by knowledgeable investors. The statistically significant change in estimated coefficients between the two periods outlined in the model clearly show developments in the Chinese market. First, the estimated lending rate coefficient had a small negative correlation with total market capitalization prior to September 1998, and its $p$-value showed it to be insignificant. In the second time period, the large negative value of the estimated coefficient and $p$-value of less than 0.01 significance show that domestic investors were becoming increasingly aware of the lending rate when making investment choices. Second, the estimated coefficient for change in consumer prices was contrary to theory, but this result is still highly significant. For the first time period, it was estimated to have a negative impact on total market capitalization, and in the second period this had changed to a positive impact. The rationale for this reaction by investors is not evident; however, the substantial shift in the relationship with total market capitalization from period one to period two clearly illustrates progress in the development of the Chinese stock market.

The estimated coefficient for the Thai baht $(T B)$ exchange rate was significant in the second period, indicating increased exposure to regional economic situations. The sign is ambiguously positive, however, indicating that the market capitalization of Chinese stock markets is positively correlated with devaluations of the Thai baht. The estimated volume coefficient $(V)$ was even smaller than the one estimated in the Hong Kong model, and was statistically insignificant. Again, liquidity measures were not insightful estimators of total stock market capitalization. Finally, as was expected, the estimated coefficient of the risk-premium variable $(T R)$ was insignificant due to lack of foreign influence in the A-share market.

\section{Forecasts for China and Hong Kong}

The final aim of this paper is to create five-year forecasts using the estimated coefficients for both the Hong Kong

\footnotetext{
${ }^{11}$ The value of the breakpoint $F$-test $(6,25)$ for China was significant at 11.299.

${ }^{12}$ Since $R^{2}<\mathrm{Dw}-\mathrm{d}$ for both models, as per the Granger and Newbold (1974) rule of thumb, it may be concluded that there is no evidence of the possible presence of spurious regression. Further investigation of correlograms (i.e., plots of autocorrelation functions against number of lags) and Dickey-Fuller tests (with alternative lag structures) also indicated the data series for both markets to be stationary. Details of these plots and test results can be obtained on a request.
} 


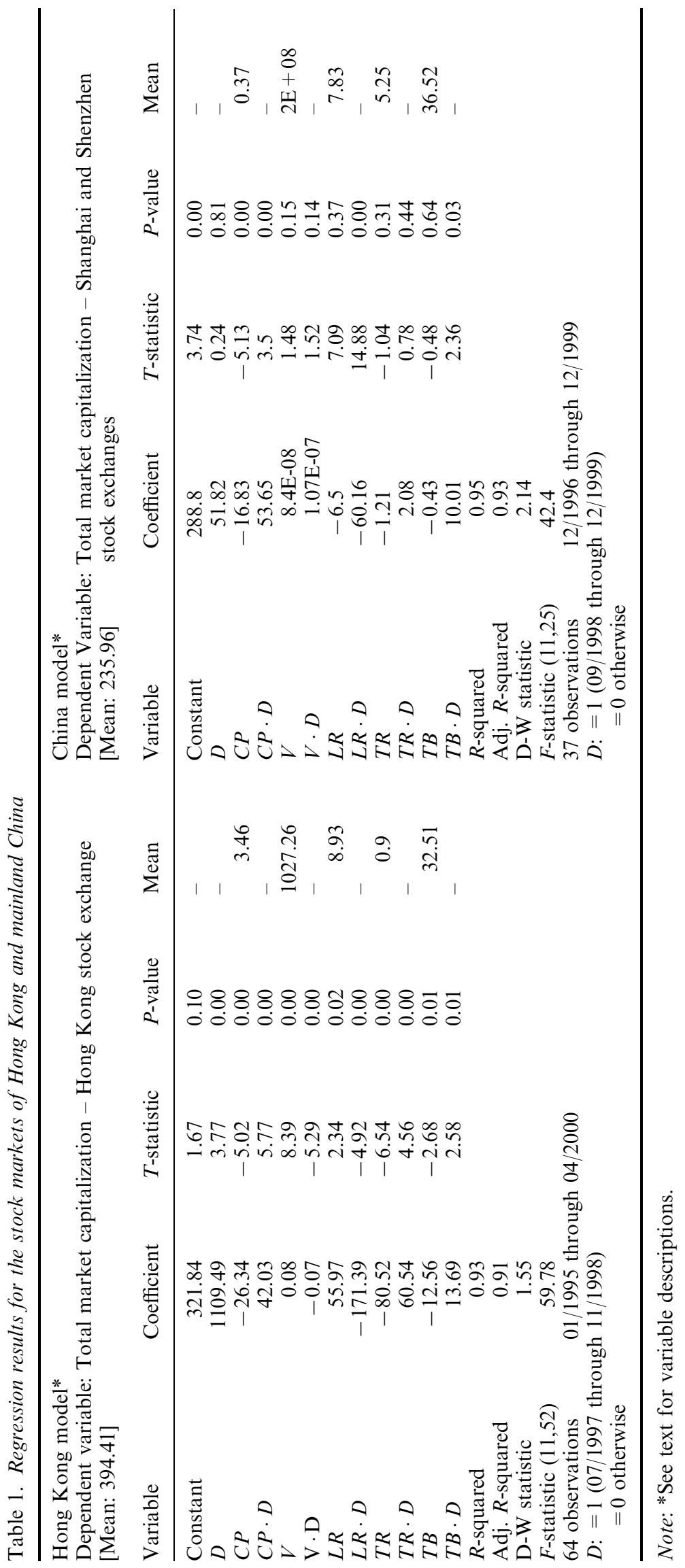


Table 2. Forecast Scenarios for the (a) Hong Kong Stock Market; (b) Mainland China Stock Market

\begin{tabular}{|c|c|c|c|}
\hline Variable & Best case & Worst case & Medium case \\
\hline \multicolumn{4}{|c|}{ Hong Kong stock exchange: forecast variables } \\
\hline \multicolumn{4}{|c|}{ Model forecast out to January 2005} \\
\hline$L R$ & 8.5 to 9.75 & increase to 10.5 , then down to 8 & 9.5 \\
\hline$T B$ & $38-39$ & slow devaluation to 42 & 38.5 \\
\hline$V$ & 1132 to 3000 & 1132 to 2500 to 3000 & $1132-1300$ \\
\hline$T R$ & decrease to 0 & 0.64 to 1.2 to 0.35 & down to 0.275 \\
\hline$C P$ & moderate deflation $(-1.5)$ & 3.5 in middle, -1.5 at end & moderate deflation $(-1.5)$ \\
\hline \multicolumn{4}{|c|}{ China stock exchange: forecast variables } \\
\hline \multicolumn{4}{|c|}{ Model forecast out to December 2004} \\
\hline$L R$ & lowers to 5.25 & increase to 10 & 5.85 to 6 \\
\hline$T B$ & slow devaluation to 43 & slow appreciation to 33 & steady 40 \\
\hline$V$ & 122334 to 790000 & increase to 300000 & increase to 450000 \\
\hline$T R$ & decrease to 2.5 from 3.8 & increase to 9 & constant 4 \\
\hline$C P$ & increase to 5 & steady 2 & moderate inflation ( 1 and 0.5 ) \\
\hline
\end{tabular}

and China models. Table $2 \mathrm{a}$ and $\mathrm{b}$ present the specifics of the three scenarios for Hong Kong and China respectively. High, low, and medium range scenarios were developed to determine a volatility band for each market, which is the difference between the high and low range market capitalization at the end of the fifth year. Based on the results of the models for Hong Kong and China, independent variables were generated out for five years that create the three scenarios. Then the estimated coefficients of each model were applied to the forecasted variables in order to determine the future total market capitalization of stock markets in Hong Kong and Mainland China.

Looking at Fig. 2a and b, the forecasted market capitalization model for China varies significantly more than that of Hong Kong. The largest spread between best and worst case scenarios for Hong Kong was US\$352 billion but for China this value was US\$614 billion. This is an indication that fluctuations in market capitalization of emerging economies have the potential to be much more volatile than those of developed economies such as Hong Kong. Interestingly, the medium range scenario for Hong Kong was worse than that of China. In the Chinese medium range scenario, volume increased and there was a situation of moderate inflation. The best-case scenario for China put its market capitalization over US\$700 billion by the end of 2004. This is a $136 \%$ increase from December 1999 to December 2004, a significantly larger increase than that of the high range scenario for Hong Kong.

\section{CONCLUSIONS}

In this paper, two empirical models were created to analyse two different economies and to test two separate hypotheses. The model for Hong Kong showed that a structural shift in the economy took place during the 1997 Asian economic crisis, and the model for China indicated that development of its stock markets has taken place. Since Hong Kong has a more developed market, this contrast of stock markets created an interesting case study from which to create a forecast the potential volatility of each respective market five years into the future.

The stock market of Hong Kong was greatly affected by the 1997 Asian crisis, and it lost almost half its value in less than one year. The vulnerability of its market contrasted greatly with the strong, continued growth of China's Ashare market. Quite clearly, these are two contrasting markets, as Hong Kong is both developed and open to foreign investors. However, a conclusion can be derived that open and developed economies are more susceptible to external shocks. China was able to survive one of the greatest financial crises in the global market place because of stringent capital controls and an inconvertible currency, and as a result, there was uninterrupted growth in the A-share market during this time period. In order to secure continued growth of its stock markets, the Chinese government needs to follow a consistent policy of market reform that includes a slow and calculated move towards reducing capital account controls and making the renminbi fully convertible. Foreign investors will thereby be able to efficiently enter and exit the Chinese stock market. Finally, the past experience of Thailand and other Asian 'Tiger' economies during the1997 Asian economic crisis can serve as a reminder to China that it needs to reform its markets in a careful and transparent manner.

In analysing the forecast scenarios for Hong Kong and China, it is clear that the Chinese stock market may well surpass the value of the Hong Kong stock exchange in the future, but it may also decline in value to a level last seen in the mid-1990s. Growth of China's stock markets is contingent upon continued economic growth amid a straightforward and consistent policy of market reform through 


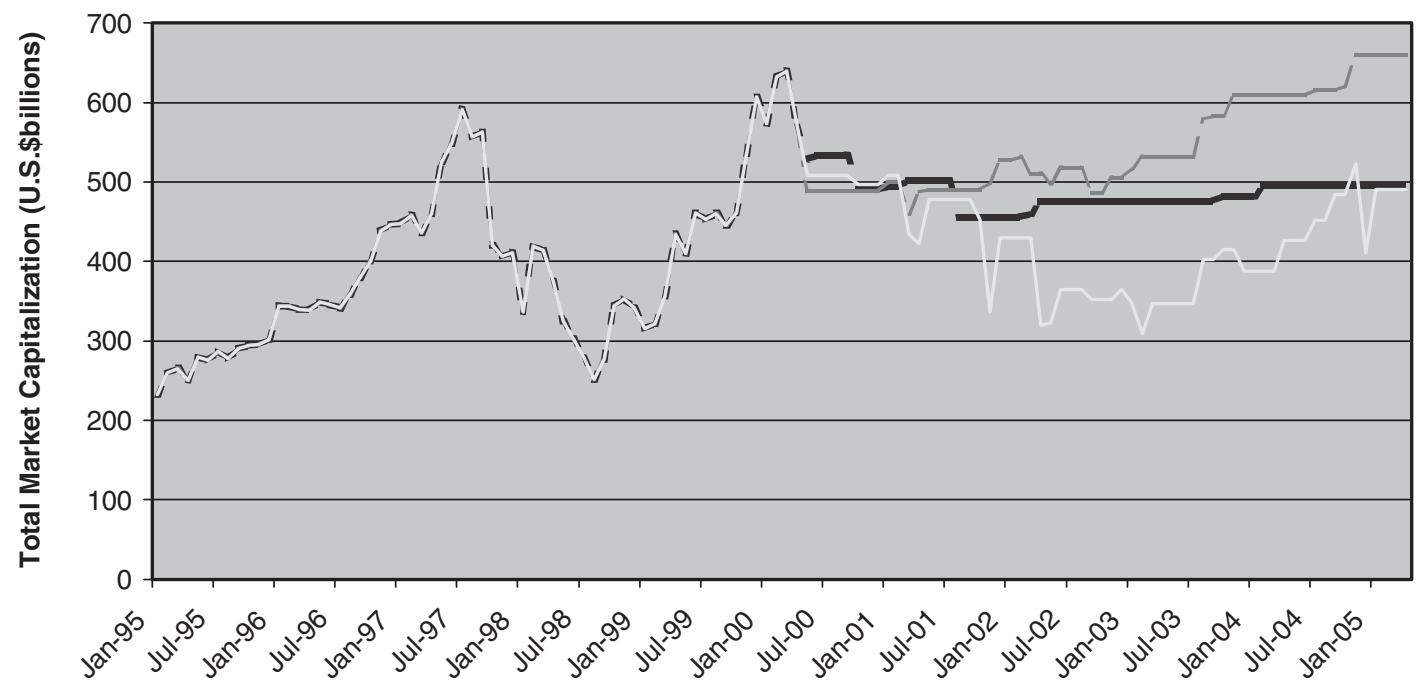

Date

$$
\text { - - - Medium Range - - - - High Range_Low Range }
$$

a

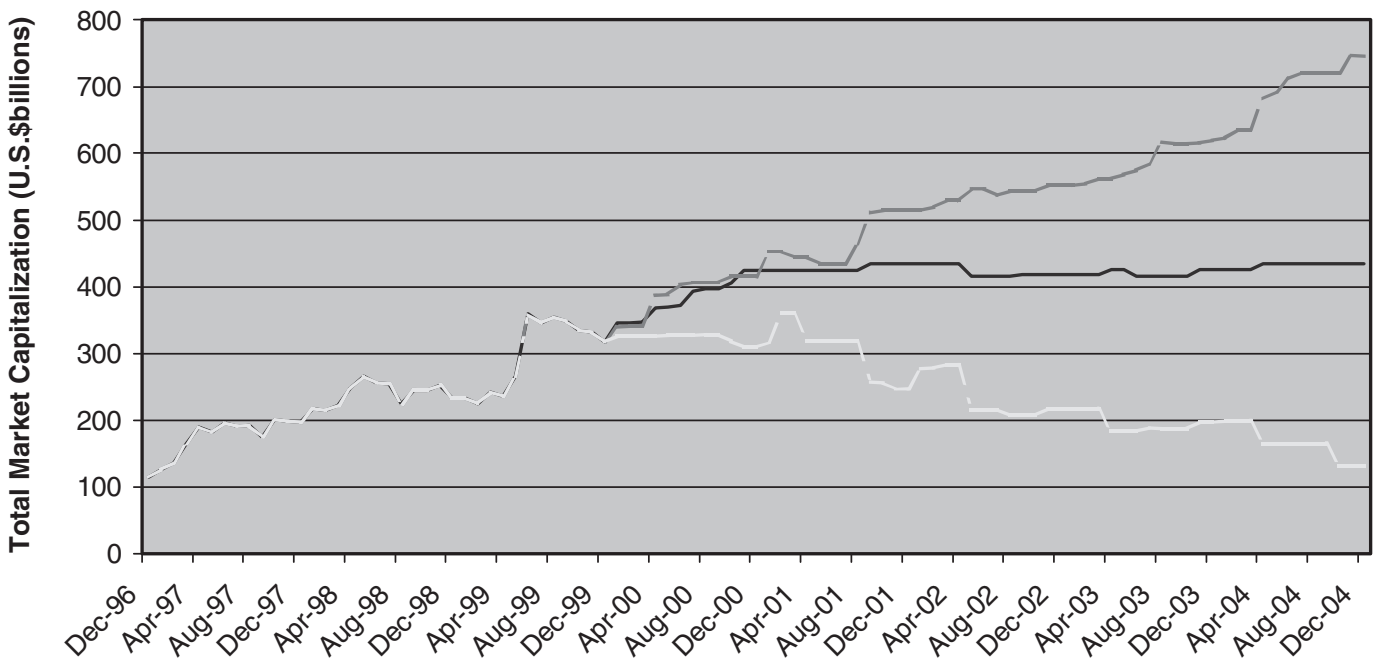

Date

—Medium Range $\quad---$ High Range _ _ Low Range

b

Fig. 2. Graph of forecasts for the (a) Hong Kong stock market, (b) mainland China stock market

desegregation of share ownership and increased transparency of economy. The relative disparities between the good and bad case scenarios for both countries show that a riskaverse global investment firm would favour Hong Kong over China. Such an investor would want to await further reforms of China's economy prior to taking up a large position in the A-share market when it is opened to foreign investors. The empirical evidence suggests development in the Chinese stock market over the past three years, but investor acknowledgment of important economic indicators in the economy have not quite reached the same level as its more developed neighbour, Hong Kong. On the other hand, investment firms willing to accept higher risk in search of higher return will favor the Chinese stock market. 


\section{ACKNOWLEDGEMENTS}

We would like to thank William Warren for his insightful comments. The usual caveat applies.

\section{REFERENCES}

Bloomberg, L. P. www.bloomberg.com.

China Securities Regulatory Commission. www.csrc.gov.cn.

Deutsche Bank AG, Hong Kong (2000) Datastream Research, October

Fernald, J., Edison, H. and Loungani, P. (1998) Was China the first domino? Assessing links between China and the rest of emerging Asia, International Finance Discussion Paper:
Board of Governors of the Federal Reserve System: Number 604, March.

Fleming, M. J. (2000) The benchmark US treasury market: recent performance and possible alternatives, Federal Reserve Bank of New York Economic Policy Review, 6(1), 129-45.

Granger, C. W. J. and Newbold, P. (1974) Spurious regression in econometrics, Journal of Econometrics, 2, 111-20.

Leggett, K. (2000) China will merge its two stock markets combined bourse will be in Shanghai; start-ups will trade in Shenzhen, The Wall Street Journal, 12 September, A23.

Ross, S. A. (1977) Return, risk and arbitrage, in Risk Return in Finance (Eds), I. Friend and J. Bicksler, Ballinger, Cambridge, MA, pp. 189-218. 